\title{
A Comprehensive Analysis of COVID-19 Transmission and Fatality Rates at the County level in the United States considering Socio-Demographics, Health Indicators, Mobility Trends and Health Care Infrastructure Attributes
}

\author{
Tanmoy Bhowmik* \\ Post-Doctoral Scholar \\ Department of Civil, Environmental \& Construction Engineering, University of Central Florida \\ Tel: 407-927-6574; Fax: 1-407-823-3315; Email: tanmoy78@knights.ucf.edu
}

ORCiD number: 0000-0002-0258-1692

\section{Sudipta Dey Tirtha}

Graduate Student

Department of Civil, Environmental \& Construction Engineering, University of Central Florida Tel: 407-543-7521; Email: sudiptadeytirtha2018@knights.ucf.edu

ORCiD number: 0000-0002-6228-0904

\section{Naveen Chandra Iraganaboina}

Graduate Student

Department of Civil, Environmental \& Construction Engineering, University of Central Florida Tel: 321-295-2134; Email: naveen.chandra@knights.ucf.edu

ORCiD number: 0000-0002-1425-6897

\section{Naveen Eluru}

Professor

Department of Civil, Environmental \& Construction Engineering, University of Central Florida Tel: 407-823-4815; Fax: 407-823-3315; Email: naveen.eluru@ucf.edu ORCiD number: 0000-0003-1221-4113

*Corresponding author 


\section{SUMMARY}

Background: Several research efforts have evaluated the impact of various factors including a) socio-demographics, (b) health indicators, (c) mobility trends, and (d) health care infrastructure attributes on COVID-19 transmission and mortality rate. However, earlier research focused only on a subset of variable groups (predominantly one or two) that can contribute to the COVID-19 transmission/mortality rate. The current study effort is designed to remedy this by analyzing COVID-19 transmission/mortality rates considering a comprehensive set of factors in a unified framework.

Method: We study two per capita dependent variables: (1) daily COVID-19 transmission rates and (2) total COVID-19 mortality rates. The first variable is modeled using a linear mixed model while the later dimension is analyzed using a linear regression approach. The model results are augmented with a sensitivity analysis to predict the impact of mobility restrictions at a county level.

Findings: Several county level factors including proportion of African-Americans, income inequality, health indicators associated with Asthma, Cancer, HIV and heart disease, percentage of stay at home individuals, testing infrastructure and Intensive Care Unit capacity impact transmission and/or mortality rates. From the policy analysis, we find that enforcing a stay at home order that can ensure a 50\% stay at home rate can result in a potential reduction of about $30 \%$ in daily cases.

Interpretation: The model framework developed can be employed by government agencies to evaluate the influence of reduced mobility on transmission rates at a county level while accommodating for various county specific factors. Based on our policy analysis, the study findings support a county level stay at home order for regions currently experiencing a surge in transmission. The model framework can also be employed to identify vulnerable counties that need to be prioritized based on health indicators for current support and/or preferential vaccination plans (when available).

\section{Funding: None.}

Keywords: COVID-19, transmission rate, mortality rate, linear mixed model, policy analysis, vulnerable counties 


\section{RESEARCH IN CONTEXT}

\section{Evidence before this study}

We conducted an exhaustive review of studies examining the factors affecting COVID-19 transmission and mortality rates at an aggregate spatial location such as national, regional, state, county, city and zip code levels. The review considered articles published in peer-reviewed journals (via PubMed and Web of Science) and working articles uploaded in preprint platforms (such as medRxiv). A majority of these studies focused on a small number of counties (up to 100 counties) and considered COVID-19 data only up to the month of April. While these studies are informative, cases in the US grew substantially in recent months. Further, earlier studies have considered factors selectively from the four variable groups - $\underline{\text { socio-demographics, health }}$ indicators, mobility trends, and health care infrastructure attributes. The exclusion of variables from these groups is likely to yield incorrect/biased estimates for the factors considered.

\section{Added value of this study}

The proposed study enhances the coverage of COVID-19 data in our analysis. Spatially, we consider 1258 counties encompassing $87 \%$ of the total population and $96 \%$ of the total confirmed COVID-19 cases. Temporally, we consider data from March $25^{\text {th }}$ to July $3^{\text {rd }}, 2020$. The model system developed comprehensively examines factors affecting COVID-19 from all four categories of variables described above. The county level daily transmission data has multiple observations for each county. To accommodate for these repeated measures, we employ a linear mixed modeling framework for model estimation. The model estimation results are augmented with policy scenarios imposing hypothetical mobility restrictions.

\section{Implications of all the available evidence}

The proposed framework and the results can allow policy makers to (a) evaluate the influence of population behavior factors such as mobility trends on virus transmission (while accounting for other county level factors), (b) identify priority locations for health infrastructure support as the pandemic evolves, and (c) prioritize vulnerable counties across the country for vaccination (when available). 


\section{INTRODUCTION}

Coronavirus disease 2019 (COVID-19) pandemic, as of July $19^{\text {th }}$, has spread to 188 countries with a reported 14.4 million cases and 603 thousand fatalities ${ }^{1}$. The pandemic has affected the mental and physical health of people across the world significantly taxing the social, health and economic systems $^{2}$. Among the various countries affected, United States has reported the highest number of confirmed cases (3.8 million) and deaths (140 thousand) in the world ${ }^{3}$. In this context, it is important that we clearly understand the factors affecting COVID-19 transmission and mortality rate to prescribe policy actions grounded in empirical evidence to slow the spread of the transmission and/or prepare action plans for potential vaccination programs in the near future. Towards contributing to these objectives, the current study develops a comprehensive framework for examining COVID-19 transmission and fatality rates in the United States using COVID-19 data at a county level encompassing about $87 \%$ of the US population. The study effort is designed with the objective of including a universal set of factors affecting COVID-19 in the analysis of transmission and mortality rates. We employ an exhaustive set of county level characteristics including (a) socio-demographics, (b) health indicators, (c) mobility trends, and (d) health care infrastructure attributes. We recognize that analysis of COVID-19 data with a subset of factors, as has been the case with earlier work, is likely to yield incorrect/biased estimates for the factors considered. The framework proposed for understanding and quantifying the influence of these factors can allow policy makers to (a) evaluate the influence of population behavior factors such as mobility trends on virus transmission (while accounting for other county level factors), (b) identify priority locations for health infrastructure support as the pandemic evolves, and (c) prioritize vulnerable counties across the country for vaccination (when available).

In recent months, a number of research efforts have examined COVID-19 data in several countries to identify the factors influencing COVID-19 transmission and mortality. Given the focus of our current study, we restrict our review to studies that explore COVID-19 transmission and mortality rate at an aggregated spatial scale. To elaborate, these studies explored COVID-19 transmission and mortality rates at the national ${ }^{4-6}$, regional $^{7}$, state $^{8}$, county $^{9-14}$, city $^{15}$ and zip code levels ${ }^{16}$. A majority of these studies considered transmission rate as the response variable (transmission rate per capita). The main approach employed to identify the factors affecting the response variables is the linear regression approach. In their analysis, researchers employed a host of independent variables from four variable categories: socio-demographics, health indicators, mobility trends and health care infrastructure attributes. For socio- demographics, studies found income, race and age distribution have a positive association with the COVID-19 transmission 11,16-18. Regarding health indicators, earlier research found that smokers, obese and individuals with existing health conditions are more likely to be severely affected by COVID-19 ${ }^{11}$. In terms of mobility trends, studies showed that staying at home and effective mobility restriction measures

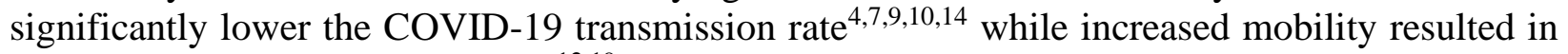
increased COVID-19 transmission ${ }^{12,19}$. Finally, among health care infrastructure attributes, testing rate is linked with reduced risk of COVID-19 transmission $^{4,5}$. While earlier research efforts have considered the factors from all variable categories, it is important to recognize that each individual study focused only on a subset of variable groups (predominantly one or two) and have not controlled explicitly for other variable groups that can contribute to the COVID-19 transmission/mortality rate. 
The current study builds on earlier literature examining the factors affecting COVID-19 transmission and mortality rate and contributes along the following directions. First, we extensively enhance the spatial and temporal coverage of COVID-19 data in our analysis. Spatially, earlier research on COVID-19 aggregate data has focused on a small number of counties (up to 100 counties). In our study, we consider all counties with total number of cases greater than 100 on July $3^{\text {rd }}$. The 1258 counties selected encompass $87 \%$ of the total population and $96 \%$ of the total confirmed COVID-19 cases. Temporally, earlier research has only considered data up to the month of April. While these studies are informative, cases in the US grew substantially in the recent months. Hence, in our study we have considered data from March $25^{\text {th }}$ to July $3^{\text {rd }}, 2020$. The longer period of data (101 days) also enables us to study/test for the evolution of variable effects over time. Second, earlier research studies have considered factors from one or two of the categories of variables identified above. Further, studies that tested health indicators employed one or two measures selectively. In our analysis, we conduct a comprehensive examination of factors affecting COVID-19 from all four categories of variables including (a) socio-demographics: distribution by age, gender, race, income, location (urban or rural), education status, income inequality and employment, (b) health indicators: percentage of population suffering from cancer, cardiovascular disease, hepatitis, Chronic Obstructive Pulmonary Disease (COPD); diabetes, obesity, Human Immunodeficiency Virus (HIV), heart disease, kidney disease, asthma; drinking and smoking habits, (c) mobility trends: daily average exposure, social distancing matrices, percentage of people staying at home, and (d) health care infrastructure attributes: hospitals per capita, ICU beds per capita, COVID-19 testing measures. Finally, the research study employs a robust modeling framework in terms of model structure and dependent variable representation. A linear mixed model system that addresses the limitations of the traditional linear regression framework for handling repeated measures is employed. For dependent variable, alternative functional forms of COVID-19 transmission - natural logarithm of daily cases per 100 thousand people and natural logarithm of 7-day moving average of cases per 100 thousand people - are considered in model estimation. The overall approach allows us to robustly quantify the impact of factors affecting COVID-19 transmission.

\section{METHODS}

\section{Data Collection}

Independent variables: Table 1 summarizes sample characteristics of the explanatory variables with the definition considered for final model estimation, the data source, and sample characteristics (minimum, maximum and mean values). For the sake of brevity, in the ensuing discussion we only present details of two groups of independent variables: health indicators and mobility trends. Using health indicator data, we ranked the 1,258 counties in a descending order of health metric and provided it in Figure 1. Further, we compute the average values for different health indicators across the healthiest and unhealthiest 10 counties to highlight the change in health conditions across the two groups. The values clearly emphasize the vulnerability of the unhealthiest counties relative to the healthiest counties. For instance, number of HIV patients in the healthy counties are 75.83 while in the unhealthiest counties, it is almost $430 \%$ higher (407). 




Figure 1 Ranking of Counties Based on Health Indicators 
To incorporate mobility trends, we considered two variables: daily average exposure ${ }^{20}$ and social distancing metric (from SafeGraph ${ }^{1}$ ) to serve as surrogate measures for the mobility patterns (see Supplementary Material for detail). Figure 2 provides a summary of both these measures at a state level from January $22^{\text {nd }}$ to July $3^{\text {rd }}$. From the figure, we can clearly see the reduction in average daily exposure in March as many states and local jurisdictions imposed lockdowns. By late April, exposure activity started to increase again across all the states while still being lower than the levels for February. In terms of the staying at home measure, as expected, we find an exactly opposite trend.
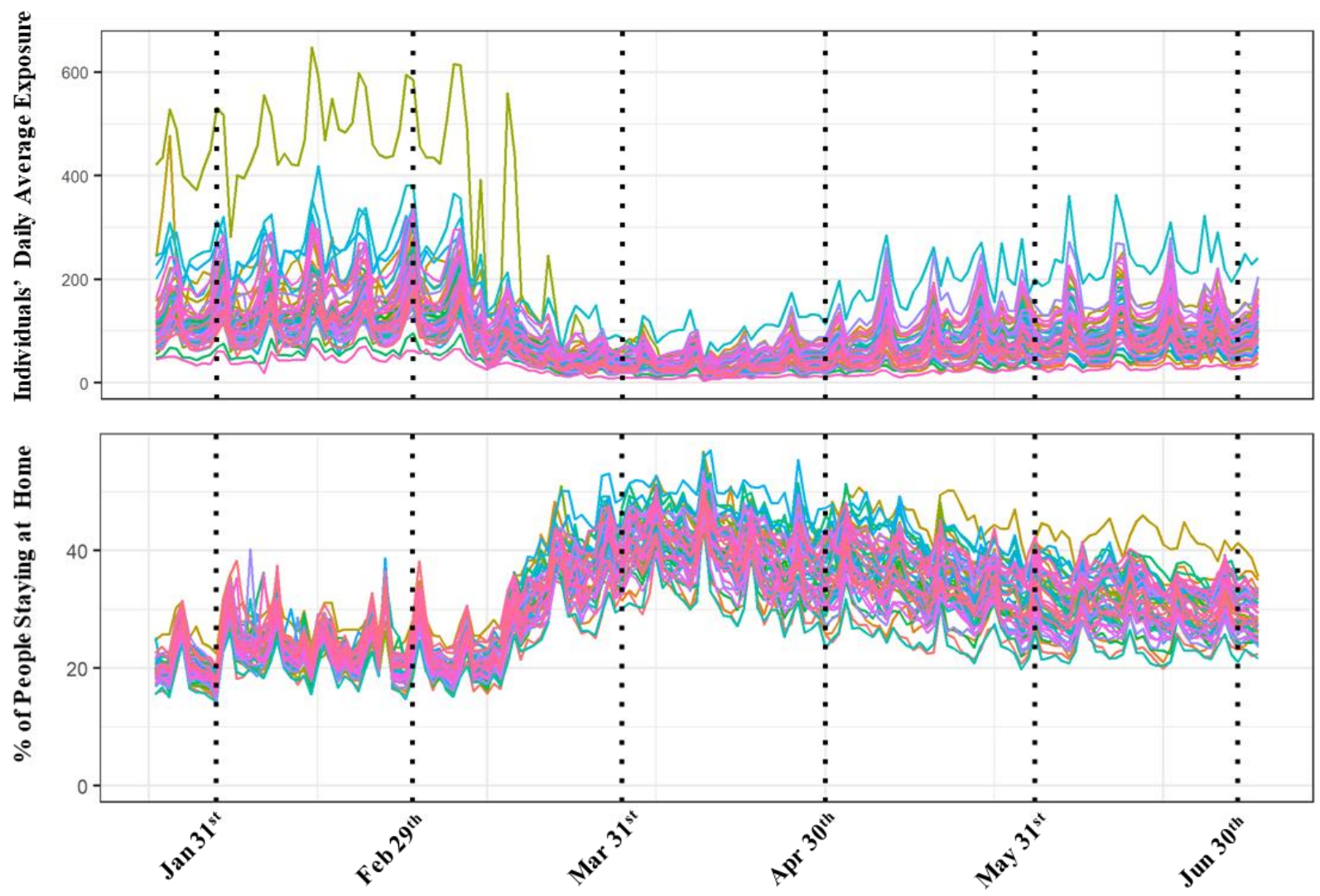

Figure 2 Average Daily Exposure and Percentage of People Staying at Home

Dependent variables: We analyze two county level dependent variables: (1) COVID-19 daily transmission rate per $100 \mathrm{~K}$ population and (2) COVID-19 mortality rates per $100 \mathrm{~K}$ population. For the transmission rate analysis, we tested two alternative functional forms: daily cases per 100 thousand people and 7-day moving average of cases per 100 thousand people. The moving average data is likely to be less volatile and serves as a stability test for the daily cases model. The reader would note that we used a natural logarithmic transformation for all the dependent variables. The COVID-19 dataset from Center for Systems Science and Engineering (CSSE) Coronavirus Resource Center at Johns Hopkins University ${ }^{21}$ provides information on the daily confirmed

\footnotetext{
${ }^{1}$ SafeGraph is a data company that aggregates anonymized location data from numerous applications in order to provide insights about physical places. To enhance privacy, SafeGraph excludes census block group information if fewer than five devices visited an establishment in a month from a given census block group
} 
COVID-19 cases, number of people recovered (when available) and the number of deaths from COVID-19 starting from January $22^{\text {nd }}$ to the current date across 3,142 counties in the United States. In our research, we confined our analysis to the cases between March $25^{\text {th }}$ to July $3^{\text {rd }}$ resulting in 101 days of data. Further, we focus on counties that have at least 100 cases by July $3^{\text {rd }}$ and have available information on the mobility trends. With this requirement, a total of 1,258 counties are included in the analysis providing a coverage of $87 \%$ of the total population in the United States. For mortality rate, we considered the fatalities within the same time frame across all the 1,258 counties as the transmission rate variable. The summary statistics of the dependent variable are presented in bottom row panel of Table 1 .

\section{Data Analysis}

For the analysis of daily COVID-19 transmission rate, we have repeated measures of the variable (101 repetitions for each county). The traditional linear regression model is not appropriate to study data with multiple repeated observations ${ }^{22}$. Hence, we employ a linear mixed modeling approach that builds on the linear regression model while incorporating the influence of repeated observations from the same county. A brief description of the linear mixed model is provided in the Supplementary Material. For modeling the COVID 19 mortality rate, we rely on simple linear regression approach as the dependent variable here is the total number of COVID-19 deaths per $100 \mathrm{~K}$ population at a county level. Both models are estimated in SPSS.

\section{Role of the Funding Source}

There was no funding source for this study.

\section{RESULTS}

COVID-19 Transmission Rate Model Results

The estimation results for the linear mixed model are presented in Table $2^{2}$.

Socio-demographics: In terms of female population, we find that higher proportion of females in the population has a positive impact on transmission rated. The result is in contrast to earlier studies that show women are less likely to be affected by COVID-19 transmission relative to men ${ }^{16}$. Among age and racial distribution proportions, we found that increased percentage of younger individuals ( $<18$ years) and African-Americans is associated with more transmission(see earlier work for similar findings $\left.{ }^{11,18}\right)$. It has been suggested that African-Americans in general reside in densely populated low income neighborhoods with lower access to amenities and are employed in industries that requires more public exposure ${ }^{17}$. Educational attainment in a county also plays an important role in influencing the COVID-19 transmission. The counties with higher share of individuals with less than high school education are likely to report increased incidence of COVID19. In terms of income, we find that higher median income counties have a higher incidence of COVID-19. The effect of income might appear counter-intuitive at first glance. However, it is possible that higher income individuals are more likely to get tested (even in the absence of symptoms) due to higher health insurance affordability. With respect to employment rate, counties with higher employment rate reflect more exposure and have a positive association with

\footnotetext{
${ }^{2}$ As discussed earlier, we also developed the same mixed linear model to estimate the 7-day moving average of COVID-19 cases per capita and find similar results as in the daily COVID-19 transmission model (results are available upon request from the authors). This further reinforces the stability of the transmission model.
} 
transmission. The percentage of people living in rural area offers a negative association with the daily COVID-19 incidence. This is intuitive as rural areas are sparsely populated and hence have more opportunity for social distancing thus lowering transmission rates.

Health indicators: With respect to health indicators, we tried several variables in the transmission rate model. Of these, two variables - number of people suffering from HIV and hepatitis $\mathrm{C}$ in a county offered significant impacts. We observe that counties with higher percentage of HIV and hepatitis C patients have an increased incidence of COVID-19 transmission. Individuals with these diseases have weaker immune systems and hence are more susceptible to COVID-19 transmission.

Mobility Trends: In terms of mobility trends, we tested two measures: daily average exposure and percentage of people staying at home. In considering these variables in the model, we recognize that exposure will have a lagged effect on transmission i.e. exposure to virus today is likely to manifest as a case in the next 5 to 14 days. In our analysis, we tested several lag combinations and selected the 10 day lag exposure as it offered the best fit. The exposure variable offers interesting results. Until April 25 ${ }^{\text {th }}$, exposure variable does not have any impact on transmission. This trend strongly coincides with the lower exposure trends (see Figure 2). After April $25^{\text {th }}$, increased exposure is associated with higher transmission rates 10 days into the future (see Hamada and colleagues ${ }^{19}$ for similar findings). For the second measure, staying at home with 14 days lag, we find that daily transmission rates are affected as expected ${ }^{4,10}$. The reader would note that the two measures considered were not found to be correlated and thus were simultaneously considered in the model.

Health Care Infrastructure Attributes: From Table 2, we find that counties with more hospitals per capita are more likely to report higher COVID-19 transmission rate. This result perhaps accounts for the higher availability of COVID-19 testing. The last set of variables within this category corresponds to COVID-19 testing effects. Again, we select a 5 day lag as testing results are likely to be reported in 3-5 days. The coefficient of this variable is positive as expected and highly significant ${ }^{4}$. However, after May $10^{\text {th }}$, the effect has a lower magnitude, which suggests that compared to the previous time period (before May $10^{\text {th }}$ ), higher testing rate will increase the daily COVID-19 transmission at a marginally lower rate.

Temporal factors: With data available for 101 days, we can evaluate the effect of the transmission rate in previous days on the current day. As expected, we find a positive association between the daily COVID-19 transmission rate and the number of cases 7 and 14 days prior. The result suggests higher transmission rate in previous time periods ( 7 and 14 days earlier) is likely to result in increased transmission. However, the effect is higher for the 7 day lagged variable, as evidenced by the higher magnitude associated with the corresponding time period in Table 2 . Further, the 7 day lagged transmission rate after June $21^{\text {st }}$ implies a higher impact perhaps explaining the sudden surge in COVID-19 cases in recent weeks. Finally, the weekend variable highlights that the COVID-19 transmission rate is lower during weekends possibly because of reduced testing rate on weekends ${ }^{23}$.

Correlation: As indicated earlier, we developed the mixed linear model for estimating the daily COVID-19 transmission rate per 100,000 people while incorporating the dependencies across each county for various repetition levels (such as week and month). We found that the model 
accommodating weekly correlations provided the best result in terms of statistical data fit and variable interpretation. The final set of variables in Table 2 corresponds to the correlation parameter across every 7 days within a county.

\section{COVID-19 Mortality Rate}

The coefficients in Table 3 represent the effect of different independent variables on COVID-19 mortality rate at a county level.

Socio-demographics: A higher percentage of older people in a county leads to an increased COVID-19 mortality rate (see ${ }^{14,18}$ for similar findings). Further, consistent with previous research $^{17}$, the current analysis also found that the percentage of African-Americans is positively associated with COVID-19 mortality rate. The variable specific to education attainment indicates that the likelihood of COVID-19 mortality increases with increasing share of people with less than high school education in a county. We find that counties with higher income inequality are more likely to experience higher number of COVID-19 deaths per capita relative to the counties with lower income disparities ${ }^{24}$. Finally, higher employment rate has a positive association with COVID-19 mortality rate.

Health Indicators: Several variables significantly influence the COVID-19 mortality rate in a county. For instance, in comparison to other counties, counties with higher number of HIV, cancer, asthma and cardiovascular patients are more likely to have higher number of COVID-19 deaths. This is expected ${ }^{25-28}$ as people with such conditions usually have weaker immune system which makes them vulnerable to the disease.

Health Care Infrastructure Attributes: The number of ICU beds per capita at a county is found to have a negative impact on COVID-19 mortality rate suggesting a reduced death rate with higher number of ICU bed per person in a county. The result is intuitive as more ICU bed per capita indicates the county is well equipped to handle higher patient demand and treatment is accessible to more COVID-19 patients.

\section{Policy Implications}

To illustrate the applicability of the proposed COVD-19 transmission model, we conduct a scenario analysis exercise by imposing mobility restrictions. While earlier researchers explored the influence of mobility measures, these models did not account for county level factors such as socio-demographics, health indicators and hospital infrastructure attributes. In our framework, the sensitivity analysis is conducted while controlling for these factors. The hypothetical restrictions on mobility are considered through the following changes to two variables:

(1) county level average daily exposure reduced by $10 \%, 25 \%$ and $50 \%$

(2) county level percentage of stay at home population increased to $40 \%, 50 \%$ and $60 \%$.

The changes to the independent variables were used to predict the dependent variable. Subsequently, the variable was converted to the daily cases per 100 thousand people. The results from this exercise are presented in Table 4 . We present the average change in cases for all counties $(1,258)$, and for the 25 counties with the highest overall transmission rates. From Table 4, two important observations can be made. First, changes to average daily exposure and stay at home population influence COVID-19 transmission significantly. In fact, by increasing stay at home population share to $50 \%$ the model predicts a reduction of the number of cases by about $30 \%$. 
Second, the benefit from mobility restrictions is slightly higher for the 25 counties with higher overall cases. The two observations provide evidence that issuing lockdown orders in counties with a recent surge is a potential mitigation measure to curb future transmission.

The COVID-19 total mortality rate model can be employed to identify vulnerable counties that need to be prioritized for vaccination programs (when available). While prioritizing the counties based on mortality rate might be a potential approach, it might not always be feasible. To elaborate, vaccination programs have to be planned well in advance (say 2 months) of the vaccine availability. As total mortality rates for 2 months into the future are unavailable, we need a model to predict total mortality into the future. The estimated mortality rate model provides a framework for such analysis. To be sure, it would be prudent to update the proposed model with the latest data to develop a more accurate prediction system.

\section{DISCUSSION}

The current study develops a comprehensive framework for examining COVID-19 transmission and fatality rates in the United States at a county level including an exhaustive set of independent variables: socio-demographics, health indicators, mobility trends and health care infrastructure attributes. In our analysis, we consider all counties with total number of cases greater than 100 on July $3^{\text {rd }}$ and analyze daily cases data from March $25^{\text {th }}$ to July $3^{\text {rd }}, 2020$. The COVID-19 transmission rate is modeled at a daily basis using a linear mixed method while the total mortality rate is analyzed adopting a linear regression approach.

Several county level factors including proportion of African-Americans, income inequality, health indicators associated with Asthma, Cancer, HIV and heart disease, percentage of stay at home individuals, testing infrastructure and Intensive Care Unit capacity impact transmission and/or mortality rates. The results clearly support our hypothesis of considering a universal set of factors in analyzing the COVID-19 data. Further we conducted policy scenario analysis to evaluate the influence of social distancing on the COVID-19 transmission rate. The results highlight the effectiveness of social distancing in mitigating the virus transmission. In fact, we found that by increasing stay at home population share to $50 \%$ the model predicts a reduction of the number of cases by about $30 \%$. The finding provides evidence that issuing lockdown orders in counties with a recent surge is a potential mitigation measure to curb future transmission.

To be sure, the study is not without limitations. The study is focused on county level analysis and is intended to reflect associations as opposed to causation. For such causation based analysis, data from individuals would be more suitable. While exposure data were reasonably addressed, data was not available for mask wearing behavior across all counties. Finally, the data on transmission and mortality are updated for few counties to correct for errors or omissions. These were carefully considered in our data preparation. However, it is possible that further updates might be made after we finished our analysis.

\section{Contributors}

NE conceptualized the study. TB and NE finalized the study design. TB, SD and NC conducted the literature review. TB, SD and $\mathrm{NC}$ collected the data. TB, SD, NC, and NE analyzed and interpreted the model results. TB, NC and SD prepared the figures. TB, SD, NC and NE drafted the main manuscript. All authors reviewed the results and approved the final version of the manuscript. 
medRxiv preprint doi: https://doi.org/10.1101/2020.08.03.20164137; this version posted August 4, 2020. The copyright holder for this preprint

(which was not certified by peer review) is the author/funder, who has granted medRxiv a license to display the preprint in perpetuity.

All rights reserved. No reuse allowed without permission.

\section{Declaration of Interests}

We declare no competing interests.

\section{Acknowledgement}

The authors would like to gratefully acknowledge SafeGraph COVID-19 Data Consortium, County Health Ranking and Road Maps, Centers for Disease Control System for providing access to the data at county level for United States.

\section{REFERENCES}

1. Worldometer. Coronavirus Cases [Internet]. [cited 2020 Jul 12]. p. 1-22. Available from: https://www.worldometers.info/coronavirus/

2. The Global Economic Outlook During the COVID-19 Pandemic: A Changed World [Internet]. [cited 2020 Jul 12]. Available from: https://www.worldbank.org/en/news/feature/2020/06/08/theglobal-economic-outlook-during-the-covid-19-pandemic-a-changed-world

3. Cases in the U.S. | CDC [Internet]. [cited 2020 Jul 12]. Available from: https://www.cdc.gov/coronavirus/2019-ncov/cases-updates/cases-in-us.html

4. Berger DW, Herkenhoff KF, Mongey S. An seir infectious disease model with testing and conditional quarantine. National Bureau of Economic Research. 2020.

5. Omori R, Mizumoto K, Chowell G. Changes in testing rates could mask the novel coronavirus disease (COVID-19) growth rate. International Journal of Infectious Diseases. 2020.

6. Yuan X, Xu J, Hussain S, Wang H, Gao N, Zhang L. Trends and Prediction in Daily New Cases and Deaths of COVID-19 in the United States: An Internet Search-Interest Based Model. Exploratory research and hypothesis in medicine. 2020;5(2):1.

7. Courtemanche CJ, Garuccio J, Le A, Pinkston JC, Yelowitz A. Did Social-Distancing Measures in Kentucky Help to Flatten the COVID-19 Curve? 2020.

8. Hu B, Gong J. Support vector machine based classification analysis of SARS spatial distribution. In: 2010 Sixth international conference on natural computation; 2010 (Vol. 2, pp. 924-927). IEEE.

9. Engle S, Stromme J, Zhou A. Staying at home: mobility effects of covid-19. Available at SSRN. 2020.

10. Bilgin NM. Tracking COVID-19 Spread in Italy with Mobility Data. Available at SSRN. 2020.

11. Mollalo A, Vahedi B, Rivera KM. GIS-based spatial modeling of COVID-19 incidence rate in the continental United States. Science of The Total Environment. 2020.

12. Sharkey P, Wood G. The Causal Effect of Social Distancing on the Spread of SARS-CoV2. 2020.

13. Wu X, Nethery RC, Sabath BM, Braun D, Dominici F. Exposure to air pollution and COVID-19 mortality in the United States. medRxiv. 2020.

14. Wieland T. Flatten the Curve! Modeling SARS-CoV-2/COVID-19 Growth in Germany on the County Level. medRxiv. 2020.

15. Xie J, Zhu Y. Association between ambient temperature and COVID-19 infection in 122 cities from China. Science of The Total Environment. 2020.

16. Borjas GJ. Demographic determinants of testing incidence and COVID-19 infections in New York City neighborhoods. National Bureau of Economic Research. 2020. 
medRxiv preprint doi: https://doi.org/10.1101/2020.08.03.20164137; this version posted August 4, 2020. The copyright holder for this preprint (which was not certified by peer review) is the author/funder, who has granted medRxiv a license to display the preprint in perpetuity.

All rights reserved. No reuse allowed without permission.

17. Backer A. Why COVID-19 May Be Disproportionately Killing African Americans: Black Overrepresentation among COVID-19 Mortality Increases with Lower Irradiance, Where Ethnicity Is More Predictive of COVID-19 Infection and Mortality Than Median Income. SSRN Electron J. 2020.

18. Xie Z, Li D. Health and Demographic Impact on COVID-19 Infection and Mortality in US Counties. Medrxiv. 2020.

19. Badr HS, Du H, Marshall M, Dong E, Squire MM, Gardner LM. Association between mobility patterns and COVID-19 transmission in the USA: a mathematical modelling study. The Lancet Infectious Diseases. 2020.

20. Couture V, Dingel JI, Green A, Handbury J, Williams KR. Measuring Movement and Social Contact with Smartphone Data: A Real-Time Application to COVID-19. University of Chicago Booth School of Business Working Paper. 2020.

21. COVID-19 Map - Johns Hopkins Coronavirus Resource Center [Internet]. [cited 2020 Jul 11]. Available from: https://coronavirus.jhu.edu/map.html

22. Faghih-Imani A, Eluru N, El-Geneidy AM, Rabbat M, Haq U. How land-use and urban form impact bicycle flows: evidence from the bicycle-sharing system (BIXI) in Montreal. Journal of Transport Geography. 2014;41:306-14.

23. Reduced testing suggested as reason for weekend drop in confirmed COVID-19 deaths | Michigan Radio [Internet]. [cited 2020 Jul 11]. Available from: https://www.michiganradio.org/post/reduced-testing-suggested-reason-weekend-dropconfirmed-covid-19-deaths

24. Income and wealth inequality in the U.S. has fueled COVID-19 deaths - MarketWatch [Internet]. [cited 2020 Jul 11]. Available from: https://www.marketwatch.com/story/income-and-wealth-inequality-in-the-us-has-fueledcovid-19-deaths-2020-06-29

25. Mehra MR, Desai SS, Kuy S, Henry TD, Patel AN. Cardiovascular disease, drug therapy, and mortality in COVID-19. New England Journal of Medicine. 2020.

26. Bansal M. Cardiovascular disease and COVID-19. Diabetes \& Metabolic Syndrome: Clinical Research \& Reviews. 2020.

27. Common Questions About the New Coronavirus Outbreak [Internet]. [cited 2020 Jul 11]. Available from: https://www.cancer.org/latest-news/common-questions-about-the-newcoronavirus-outbreak.html

28. Zhang L, Zhu F, Xie L, Wang C, Wang J, Chen R, Jia P, Guan HQ, Peng L, Chen Y, Peng P. Clinical characteristics of COVID-19-infected cancer patients: a retrospective case study in three hospitals within Wuhan, China. Annals of Oncology. 2020.

29. The COVID-19 tracking project [Internet]. [cited 2020 June 12]. Available from: https://covidtracking.com/data/. 
Table 1 Descriptive Statistics of the Dependent and Independent Variables

\begin{tabular}{|c|c|c|c|c|}
\hline Variables & Source & Mean & Min/Max & $\begin{array}{l}\text { Sample } \\
\text { Size }\end{array}$ \\
\hline \multicolumn{5}{|c|}{ Independent Variables } \\
\hline \multicolumn{5}{|l|}{ Demographic Characteristics } \\
\hline Percentage of population aged 18 years and lower & $\mathrm{ACS}^{\mathrm{a}}$ & $22 \cdot 705$ & $7 \cdot 155 / 33 \cdot 882$ & 1258 \\
\hline Percentage of population aged 65 years and over & $\mathrm{ACS}$ & $16 \cdot 644$ & $7 \cdot 545 / 56 \cdot 944$ & 1258 \\
\hline Percentage of African American & $\mathrm{ACS}$ & $13 \cdot 133$ & $0 \cdot 113 / 80 \cdot 507$ & 1258 \\
\hline Percentage of Hispanic & $\mathrm{ACS}$ & $11 \cdot 331$ & $0 \cdot 623 / 96 \cdot 323$ & 1258 \\
\hline Percentage of Female & $\mathrm{ACS}$ & $50 \cdot 507$ & $37 \cdot 041 / 54 \cdot 495$ & 1258 \\
\hline Ln (Median income) & $\mathrm{ACS}$ & $10 \cdot 903$ & $10 \cdot 150 / 11 \cdot 820$ & 1258 \\
\hline Percentage of people less than high school education & $\mathrm{ACS}$ & $14 \cdot 003$ & $3 \cdot 127 / 47 \cdot 053$ & 1258 \\
\hline Employment rate per capita & $\mathrm{ACS}$ & $0 \cdot 446$ & $0 \cdot 195 / \cdot 634$ & 1258 \\
\hline Income inequality ratio $\left(80^{\text {th }}\right.$ percentile $/ 20^{\text {th }}$ percentile $)$ & $\mathrm{CHRR}^{\mathrm{b}}$ & $4 \cdot 574$ & $3 \cdot 150 / 9 \cdot 148$ & 1258 \\
\hline \multicolumn{5}{|l|}{ Health Indicators } \\
\hline Ln (HIV Prevalence Rate per $100 \mathrm{~K}$ people) & CHRR & $5 \cdot 043$ & $0 \cdot 723 / 7 \cdot 859$ & 1258 \\
\hline Hepatitis B Cases per $100 \mathrm{~K}$ people in 2017 & $\mathrm{CDC}^{\mathrm{c}}$ & $1 \cdot 250$ & $0 \cdot 000 / 11 \cdot 700$ & 1258 \\
\hline Hepatitis C Cases per $100 \mathrm{~K}$ people in 2017 & $\mathrm{CDC}$ & 0.980 & $0 \cdot 000 / 5 \cdot 600$ & 1258 \\
\hline Asthma $\%$ for $>=18$ years & $\mathrm{CDC}$ & $9 \cdot 328$ & $7 \cdot 400 / 12 \cdot 300$ & 1258 \\
\hline COPD $\%$ for $>=18$ years & $\mathrm{CDC}$ & $6 \cdot 692$ & $3 \cdot 300 / 13 \cdot 700$ & 1258 \\
\hline Reported cancer case per $100 \mathrm{~K}$ people & $\mathrm{CDC}$ & $455 \cdot 918$ & $241 \cdot 000 / 576 \cdot 400$ & 1258 \\
\hline Percentage of diabetic & CHRR & $11 \cdot 353$ & $3 \cdot 300 / 20 \cdot 400$ & 1258 \\
\hline Percentage of obesity among adults & CHRR & $31 \cdot 653$ & $13 \cdot 600 / 46 \cdot 700$ & 1258 \\
\hline $\begin{array}{l}\text { Cardiovascular Disease Hospitalization Rate per 1,000 } \\
\text { Medicare Beneficiaries }\end{array}$ & $\mathrm{CDC}$ & $63 \cdot 609$ & $0 \cdot 300 / 110 \cdot 500$ & 1258 \\
\hline \multicolumn{5}{|l|}{ Mobility Trends } \\
\hline \multicolumn{5}{|l|}{ Ln (Daily Average Exposure), 10 days lag } \\
\hline From April 25th & $\mathrm{CEI}^{\mathrm{d}}$ & $3 \cdot 325$ & $0 \cdot 102 / 0 \cdot 644$ & 127058 \\
\hline \multicolumn{5}{|l|}{$\%$ People staying at home } \\
\hline 14 days lag & Safegraph & $4 \cdot 128$ & $0 \cdot 847 / 7 \cdot 049$ & 127058 \\
\hline \multicolumn{5}{|l|}{ Healthcare Related Attributes } \\
\hline Hospitals per $100 \mathrm{~K}$ people & CHRR & 1.967 & $0 \cdot 000 / 15 \cdot 644$ & 1258 \\
\hline Number of ICU beds per capita & CHRR & $20 \cdot 111$ & $0 \cdot 000 / 171 \cdot 850$ & 1258 \\
\hline Ln (No of tests with 5 days lag) & $\mathrm{CTP}^{\mathrm{e}}$ & $11 \cdot 178$ & $4 \cdot 320 / 15 \cdot 190$ & 5151 \\
\hline \multicolumn{5}{|l|}{ Temporal Factors } \\
\hline Day is weekend & +- & $0 \cdot 277$ & $0 \cdot 000 / 1 \cdot 000$ & 127058 \\
\hline \multicolumn{5}{|c|}{ Dependent Variables } \\
\hline $\begin{array}{l}\text { Ln (Daily COVID-19 transmission rate per } 100 \mathrm{~K} \\
\text { people) }\end{array}$ & $\operatorname{CSSE}^{\mathrm{f}}$ & $1 \cdot 455$ & $0 \cdot 000 / 7 \cdot 670$ & 127058 \\
\hline Ln (Total COVID-19 mortality rate per $100 \mathrm{~K}$ people) & CSSE & $2 \cdot 722$ & $0 \cdot 000 / 7 \cdot 120$ & 1258 \\
\hline $\begin{array}{l}a=\text { American Community Survey } \\
b=\text { County Health Rankings \& Roadmaps } \\
b^{c}=\text { Central for Disease Control System } \\
d^{d}=\text { COVID Exposure Indices }{ }^{20} \\
{ }^{e}=\text { COVID-19 Tracking Project }{ }^{29} \\
{ }^{f}=\text { Center for Systems Science and Engineering Coronavir }\end{array}$ & so & & Honk & \\
\hline
\end{tabular}


Table 2 Estimation Results for Daily COVID-19 Transmission Rate per 100K Population

\begin{tabular}{|c|c|c|c|}
\hline Variables & Estimates & t-statistic & p-value \\
\hline Constant & $-6 \cdot 071$ & $-16 \cdot 215$ & $0 \cdot 000$ \\
\hline \multicolumn{4}{|l|}{ Demographics } \\
\hline$\%$ of Female population & $0 \cdot 024$ & $7 \cdot 496$ & $0 \cdot 000$ \\
\hline$\%$ Young population $(<=18$ years $)$ & $0 \cdot 005$ & $2 \cdot 524$ & $0 \cdot 012$ \\
\hline$\%$ of Black population & 0.007 & $15 \cdot 061$ & 0.000 \\
\hline$\%$ of People less than high school education & 0.025 & $18 \cdot 454$ & $0 \cdot 000$ \\
\hline Ln (median income) & $0 \cdot 396$ & $12 \cdot 650$ & $0 \cdot 000$ \\
\hline Employment rate per capita & $1 \cdot 409$ & $9 \cdot 640$ & $0 \cdot 000$ \\
\hline Ln (\% of People living in rural areas) & $-0 \cdot 309$ & $-9 \cdot 249$ & $0 \cdot 000$ \\
\hline \multicolumn{4}{|l|}{ Health Indicators } \\
\hline Ln (HIV rate per $100 \mathrm{~K}$ People) & $0 \cdot 052$ & $6 \cdot 306$ & $0 \cdot 000$ \\
\hline Hepatitis C rate per $100 \mathrm{~K}$ People & $0 \cdot 027$ & $5 \cdot 152$ & $0 \cdot 000$ \\
\hline \multicolumn{4}{|l|}{ Mobility Trends } \\
\hline \multicolumn{4}{|l|}{ Ln (Daily Average Exposure), 10 days lag } \\
\hline From April 25th & 0.027 & $9 \cdot 618$ & $0 \cdot 000$ \\
\hline \multicolumn{4}{|l|}{$\%$ People staying at home } \\
\hline 14 days lag & $-1 \cdot 027$ & $-7 \cdot 690$ & $0 \cdot 000$ \\
\hline \multicolumn{4}{|l|}{ Health Care Infrastructure Attributes } \\
\hline Hospital per $100 \mathrm{~K}$ People & 0.028 & 8.958 & $0 \cdot 000$ \\
\hline \multicolumn{4}{|l|}{ Ln (Testing), 5 days lag } \\
\hline March $25^{\text {th }}$ to May 10th & $0 \cdot 020$ & $10 \cdot 481$ & $0 \cdot 000$ \\
\hline After May 10th & $0 \cdot 016$ & $7 \cdot 155$ & $0 \cdot 000$ \\
\hline \multicolumn{4}{|l|}{ Temporal Factors } \\
\hline \multicolumn{4}{|l|}{ Temporal Lagged Variables } \\
\hline 7 days lag (March $25^{\text {th }}$ to June $21^{\text {st }}$ ) & $0 \cdot 205$ & $68 \cdot 500$ & 0.000 \\
\hline 7 days lag (After June $21^{\text {st }}$ ) & $0 \cdot 340$ & $60 \cdot 026$ & 0.000 \\
\hline 14 days lag & $0 \cdot 148$ & $50 \cdot 225$ & $0 \cdot 000$ \\
\hline Day is Weekend & $-0 \cdot 033$ & $-5 \cdot 925$ & $0 \cdot 000$ \\
\hline \multicolumn{4}{|l|}{ Correlation } \\
\hline$\sigma$ & 0.973 & $194 \cdot 881$ & 0.000 \\
\hline$\rho$ & 0.960 & $305 \cdot 240$ & $0 \cdot 000$ \\
\hline$\Phi$ & $0 \cdot 321$ & 83.977 & 0.000 \\
\hline
\end{tabular}


Table 3 Estimation Results for COVID-19 Mortality Rate per 100K Population

\begin{tabular}{|c|c|c|c|}
\hline Variables & Estimates & t-statistic & p-value \\
\hline Constant & $-6 \cdot 952$ & $-7 \cdot 715$ & $0 \cdot 000$ \\
\hline \multicolumn{4}{|l|}{ Demographics } \\
\hline Older people $\%$ (>65 years old $)$ & $0 \cdot 068$ & $6 \cdot 649$ & $0 \cdot 000$ \\
\hline Black people\% & $0 \cdot 018$ & $5 \cdot 749$ & $0 \cdot 000$ \\
\hline$\%$ of People less than high school education & $0 \cdot 050$ & $6 \cdot 153$ & $0 \cdot 000$ \\
\hline Employment rate per capita & $8 \cdot 369$ & $7 \cdot 853$ & $0 \cdot 000$ \\
\hline Income inequality ratio & $0 \cdot 274$ & $4 \cdot 795$ & $0 \cdot 000$ \\
\hline Ln (\% of People living in rural areas) & $-0 \cdot 772$ & $-3 \cdot 173$ & $0 \cdot 002$ \\
\hline \multicolumn{4}{|l|}{ Health Indicators } \\
\hline Ln (HIV rate per $100 \mathrm{~K}$ people) & $0 \cdot 082$ & $1 \cdot 557$ & $0 \cdot 120$ \\
\hline Cancer rate per $100 \mathrm{~K}$ people & 0.003 & $3 \cdot 397$ & $0 \cdot 001$ \\
\hline$\%$ People having Asthma & $0 \cdot 091$ & $2 \cdot 720$ & $0 \cdot 007$ \\
\hline Cardiovascular disease per $1 \mathrm{~K}$ people & $0 \cdot 007$ & $2 \cdot 304$ & $0 \cdot 021$ \\
\hline \multicolumn{4}{|l|}{ Health Care Infrastructure Attributes } \\
\hline ICU beds per capita & -0.009 & $-4 \cdot 794$ & $0 \cdot 000$ \\
\hline
\end{tabular}

Table 4 Policy Scenario Analysis of Social Distancing in COVID-19 Transmission Rate per 100K Population

\begin{tabular}{||l|c|c||}
\hline \hline Hypothetical Scenarios & $\begin{array}{c}\mathbf{1 , 2 5 8} \\
\text { Counties }\end{array}$ & $\begin{array}{c}\text { Worst 25 } \\
\text { Counties }\end{array}$ \\
\hline \hline 1: daily average exposure reduced by 10\% & $-0 \cdot 225$ & $-0 \cdot 240$ \\
\hline 2: daily average exposure reduced by 25\% & $-0 \cdot 612$ & $-0 \cdot 653$ \\
\hline 3: daily average exposure reduced by 50\% & $-1 \cdot 465$ & $-1 \cdot 565$ \\
\hline 4: $40 \%$ people stay at home & $-22 \cdot 949$ & $-23 \cdot 206$ \\
\hline 5: 50\% people stay at home & $-30 \cdot 469$ & $-30 \cdot 701$ \\
\hline 6: $60 \%$ people stay at home & $-37 \cdot 256$ & $-37 \cdot 465$ \\
\hline
\end{tabular}

